\title{
O Uno e o Ser no Pensamento DE Meister EckHarT
}

\author{
Matteo Raschietti ${ }^{1}$
}

RESUMO: O problema de fundo da especulação eckhartiana é a verdade do ser uno enquanto Deus e divino ligada à questão do seu conhecimento. Operando uma síntese da tradição neoplatônicoagostiniana e do pensamento do Pseudo-Dionísio Areopagita, o mestre dominicano funda os alicerces da sua teologia unitiva na teoria do ser.

PALAVRAS-CHAVE: Uno. Ser. Conhecimento. Analogia. Causalidade.

\section{INTRODUÇÃo}

Todo o pensamento eckhartiano é dominado pela exigência absoluta da unidade. No dogma da Trindade, o mestre dominicano, além de encontrar o uno e a vida, opera uma distinção entre Divinitas (Gottheit) e Deus (Gott): "Direi mais uma coisa, que eu nunca disse: Deus e a Divindade estão tão longe um da outra e são diferentes como o céu da terra” (Pr. 26). ${ }^{2}$

Gottheit correponde àquele fundo (Grund) onde não há nenhuma distinção, nenhuma alteridade, nenhuma operação, nenhuma relação, nenhum nome. Gott, ao invés, é essentia cum relatione, principium, atividade que se exterioriza, assumindo o nome de Pai (na Trindade) e de criador (cuja

\footnotetext{
${ }^{1}$ Professor do Departamento de Filosofia, UNESP - Marília). Nascido em Vicenza, Itália, em 1968, resolveu enveredar-se pelos caminhos da Filosofia e da Teologia, depois do diploma de perito eletrotécnico. Chegou ao Brasil há mais de vinte anos e concluiu o curso de Teologia na Faculdade Nossa Senhora da Assunção, em Sáo Paulo. Em 1998, retomou os estudos filosóficos na UNICAMP, graças ao professor Francisco Benjamin de Souza Netto, seu orientador no Mestrado e Doutorado. Sua primeira publicação foi a tradução do De diligendo deo, de São Bernardo.

${ }^{2}$ Publicado por Pfeiffer (Deutsche Mystiker, II) com o número LVI, o sermão já fora reconhecido como autêntico por Quint e inserido, com o número 26, na sua obra Deutsche Predigten und Traktate com o número 26. Na grande edição crítica em fase de preparação, terá o número 109 . É com certeza um dos textos mais densos e significativos de Eckhart.
} 
obra se renova a todo instante, vive nas criaturas e se reconhece nelas). A Divinitas inefável de Eckhart permanece incognoscível e indizível enquanto ser e essência, assim como o uno de Plotino foge a todo conhecimento e toda denominação, porque absolutamente idêntico a ele mesmo. Para Eckhart, o ser não é o nome próprio dessa Divinitas inominável, assim como o uno de Plotino não é um nome adequado para nomear o indizível, mas os dois prestam explicaçóes diferentes à inefabilidade:

[...] o ser de Eckhart é indizível porque indistinto, o uno de Plotino é indizível porque se distingue de tudo aquilo que é. Situando o uno após o ser inominável, Eckhart lhe presta um sentido novo que não poderia haver na tradiçáo puramente plotiniana. $\mathrm{O}$ uno se torna o primeiro nome divino, princípio único de todos os nomes, de toda expressão do inexprimível. (LOSSKY, 1998, p. 64).

Em Meister Eckhart, a essência divina (Deus sub ratione esse) corresponde, de uma certa forma, ao "uno que não é" plotiniano. Com efeito, não apenas a essência é indizível, mas também sua indeterminação absoluta não poderia ser oposta a qualquer realidade, inclusive ao não-ser. $\mathrm{O}$ uno eckhartiano é, ao mesmo tempo, princípio e intelecto do Pai, contendo as razóes de todas as coisas no Verbum e reduzindo-as à unidade. Lossky, fazendo referência ao intelecto Paternal, escreve que o intelecto humano descobre no interior das coisas criadas "[...] os princípios primeiros de sua cognoscibilidade e de seu ser, princípios que são a irradiação das razóes criadas nas trevas das criaturas" (LOSSKY, 1998, p. 83). Essa unidade divina, que tudo compreende, é representada por Eckhart com o símbolo geométrico da esfera intelectual infinita, cujo centro está em todo lugar e a circunferência em toda parte.

\section{O UNO COMO CAUSA DIVINA DE TODAS AS PERFEIÇÓES CRIADAS}

Querendo dar a essa perfeição suprema um nome através do qual e no qual se pudesse ver tudo, esse nome deveria ser necessariamente "uno". O Deus bíblico recebe, assim, seu nome escatológico de raízes neoplatônicas: “[...] este nome 'acima de todos os nomes' não é o 'nome inominável' de Deus: é seu único nome, singular, assemelhando todas as perfeiçôes. O uno-essência considerado por Eckhart é o quo est, a causa divina de todas as perfeiçóes 
criadas" (LOSSKY, 1998, p. 88). Essa henologia ${ }^{3}$ é a razão última da teologia negativa eckhartiana, e não consiste apenas em pôr o uno no lugar do nome de Deus (porque, ainda que fosse utilizado com uma conotação negativa, não seria capaz de nomear Deus). Como afirma De Libera, "[...] todo nome, mesmo aquele de um, é um simples núncio” (DE LIBERA, 1984, p. 284):

Eckhart deriva nomen de notitia (conhecimento). O nome é um "núncio" que anuncia (nuntiat) um conceito do intelecto em notificando (notificat: notum-fieri, fazer conhecer) a alguém. A palavra "um" une a ideia de ser àquela de provação ou de distinção ao nível conceitual (secundum intentionem) e não ao nível real (secundum rem). De outro modo diz: ser um ser, é não ser um outro ser. $\mathrm{O}$ "um" que Eckhart rejeita aqui é, pois, o "um" que diz respeito ao ser in re (na coisa), mas diferente dele, secundum intentionem. É o "um transcendental" de Aristóteles, não o "um transcendente" dos filósofos platônicos. (DE LIBERA, 1984, p. 313).

A verdade do ser uno enquanto Deus e divino, junto à questão do seu conhecimento, são os polos que articulam o problema de fundo da especulação eckhartiana que culmina na proposta de uma experiência espiritual do ser. Meister Eckhart funda os alicerces da sua teologia unitiva na teoria do ser, operando uma síntese de duas tradiçóes distintas: a neoplatônico-agostiniana, cuja ideia central é a concepção de Deus como ipsum esse per se subsistens qui solus vere est, e a dionisiana ${ }^{4}$, que converge na infinita transcendência inefável do Deus-Uno. De acordo com a articulação sintética dessas duas tradiçóes, a realidade divina brilha na luz infinita de sua simplicidade e se oculta na sombra simples da sua infinidade:

Deus é infinito em sua simplicidade e simples em sua infinidade. Por isso está em toda parte e em toda parte todo inteiro. Em toda parte mercê de sua infinidade, mas todo inteiro em toda parte mercê de sua simplicidade. Só Deus se efunde em todas as coisas, em suas essências. Das demais coisas, porém, nenhuma se infunde em outra. Deus está no mais íntimo de cada coisa, e só no mais íntimo, e somente ele é um. Cumpre notar que cada criatura ama em Deus o um e o ama por causa do um, e o ama porque é

\footnotetext{
${ }^{3}$ Do grego henós: uno (hén, neutro de heîs - "um"), isto é, a doutrina do uno, princípio primo e absoluto e explicação de toda realidade.

${ }^{4}$ Dionísio Pseudo-Areopagita foi considerado, até 1800, o discípulo de são Paulo convertido em 51 d.C. pelo discurso do apóstolo no Areópago que, em seguida, se tornou o primeiro bispo de Atenas. Na realidade, sob o nome de Dionísio se esconde um autor cristáo grego que viveu entre o fim do século V e a metade do século VI d.C., cuja identidade permanece ainda desconhecida. A ele é atribuído um conjunto de obras de teor neoplatônico, que desempenhou um papel importante na retomada da atividade filosófica do Ocidente, sobretudo no que se conhece como renascimento carolíngio.
} 
um. Primeiro, porque tudo o que é, ama e busca a semelhança com Deus. A semelhança, porém, é uma certa unidade ou a unidade de certas coisas. Segundo, (porque) no um jamais há dor ou pena ou enfado, e nem sequer há nele passibilidade ou mortalidade. Terceiro, porque no um, enquanto é um, estão todas as coisas. Pois toda multidão é uma e um, no Um e pelo Um. E, quarto, porque não amaríamos nem o poder nem a sabedoria nem a bondade como tal, nem mesmo o ser, se não se unissem conosco e nós com eles. Quinto, porque o que ama verdadeiramente só pode amar um só. Por isso, à palavra Deus é um segue-se outra: "Amarás ao Senhor teu Deus com todo o teu coraçáo" (Dt 6,5). E, sem dúvida, (o que ama) quer que aquilo que ele ama com todo o seu ser seja um só. Sexto, porque ele quer se unir ao amado. O que não lhe é possível se este não for um. Além disso, Deus só une a si porque é um e enquanto é um. Além disso, pelo mesmo fato de ser um, ele deve necessariamente unir todas as coisas e uni-las em si e consigo. Sétimo, porque o um é indistinto de todas as coisas. Logo, nele, em razão da indistinçáo ou unidade, estấo todas as coisas e a plenitude do ser. Oitavo: repara bem que o um, em sentido próprio, diz respeito ao todo e ao perfeito. Pelo que, mais uma vez, nada lhe falta. Nono: nota que o um, por essência, se refere ao próprio ser ou à essência - ou mais exatamente, à essência uma. Pois também a essência é sempre uma só, e em razão da unidade compete-lhe a uniáo ou o ser unido. Cumpre notar, portanto, que aquele que verdadeiramente ama a Deus como ao um e por causa do um e da uniáo, de modo algum se preocupa ou interessa pela onipotência ou pela sabedoria de Deus, porque estas pertencem a vários e dizem respeito a coisas várias. Tampouco se preocupa com a bondade em geral: primeiro, porque ela se refere ao que é exterior e está nas coisas e, segundo, porque a bondade consiste na adesão: "aderir a Deus, para mim, é o bem” (S1 72,28). Décimo: nota que o um é mais alto, anterior e mais simples do que o bom, e está mais perto do ser e de Deus; ou, antes, consoante o seu nome, é um só ser com o próprio ser. Undécimo: Deus é profusamente rico por isso que é um. Com efeito, Ele é o primeiro e o supremo pela simples razão de ser uno. Por isso o um desce para todas as coisas e para cada coisa singular, mas continuando sempre a ser um e unindo as coisas separadas. Por isso o seis não é duas vezes três, mas seis vezes um. (ECKHART, Sermo 29).

Deus, na sua transcendência imanente, não perde sua unicidade quando se une às criaturas. Essa união, entretanto, exige que a criatura se anule na sua individualidade, "[...] pois só através desse exercício rigoroso de despojamento de si pode chegar a possuir-se segundo a unidade indivisa do ser que é Deus, no uno pelo qual e no qual exclusivamente se funda, de forma estável, o ser" (CAVICCHIOLI, 1997, p. 426). Toda criatura, escreve Eckhart no Comentário ao Gênesis, 
[...] tem um duplo ser. Um nas suas causas originárias, pelo menos na palavra de Deus, e esse é o ser fixo e estável [...] O outro é o ser que as coisas possuem fora, na natureza, o ser que elas possuem em sua forma própria. O primeiro é um ser virtual, o segundo é um ser formal que, frequentemente, é instável e variável. (ECKHART, In Gen. 77).

Não há dúvida de que, para Eckhart, só o primeiro ser propriamente é, enquanto o segundo ser, múltiplo e exterior (esse hoc vel hoc creatum), representa um "[...] estado de total privação ontológica, em si decadência real da unidade do único ser divino e dispersão no não-ser da regio dissimilitudinis infinita de matriz agostiniana" (CAVICCHIOLI, 1997, p. 426). Além de Agostinho, Eckhart chama em causa Proclo, para quem as coisas participam do ser-uno e são enquanto estão no ser-uno: "Toda multiplicidade recebe seu ser e subsiste no ser na unidade, ou seja, no uno e desde o uno. 'Pois todo múltiplo', como diz Proclo, 'participa do uno'. Mas Deus é uno” (In Gen. 114).

\section{ESSE EST DEUS}

Baseando-se nessa teoria, Eckhart não aceita qualquer representação positiva do ser criado em si, porque isso implicaria uma sua impossível autossuficiência distinta daquela divina. Só em Deus, único ser (não havendo nenhum outro ser fora dele), existe a capacidade de ser em sentido próprio.

O coração dessa ontologia se encontra no Opus Tripartitum, obraprima de sua extensa produção acadêmica. Apesar de não se dispor da obra de Eckhart integralmente, é possível reconstruir seus temas principais a partir dos títulos dos quatorze tratados do Opus tripartitum citados no Prologus generalis:

O primeiro tratado se ocupa do ser e do ente, e do seu oposto que é o nada.

O segundo da unidade e do uno, e do seu oposto que é o múltiplo.

O terceiro da verdade e do verdadeiro, e do seu oposto que é o falso.

O quarto da bondade e do bem, e do mal que é seu oposto.

O quinto do amor e da caridade, e do pecado que é seu oposto.

O sexto do honesto, da virtude e do direito, e de seus opostos, por exemplo, o torpe, o vício e o errado.

O sétimo do todo e da parte, que é seu oposto.

$\mathrm{O}$ oitavo do comum e do indistinto, e de seus opostos, o próprio e o distinto.

O nono da natureza superior e inferior, e de seus opostos.

O décimo do primeiro e do último. 
O décimo primeiro da ideia e da razão, e de seus opostos, por exemplo, do informe e da privação.

O décimo segundo daquilo pelo qual é, e do que é, seu correlativo.

$\mathrm{O}$ décimo terceiro trata de Deus mesmo, o ser mais elevado, que «não tem contrário, exceto o não-ser», como diz Agostinho no De immortalitate animae e no De mortibus manichaeorum.

O décimo quarto da substância e do acidente. (ECKHART, Prologus generalis).

Nos primeiros quatro tratados dessa lista, que versam sobre o ser e os transcendentais (unidade, verdade e bondade), pode-se reconhecer um conjunto fechado de extrema importância na metafísica eckahrtiana. $\mathrm{O}$ leitmotiv que permite sua compreensão é a equação esse est Deus:

O ser é Deus. Esta proposição é evidente. Primeiramente porque, se o ser for diverso do próprio Deus, Deus não é nem é Deus. De que modo, afinal, poderia ser e ser algo, se o ser fosse outro, alheio e distinto dele? $\mathrm{Ou}$, se for Deus, é Deus por causa de outro, sendo o ser outro dele mesmo. Portanto Deus e o ser são o mesmo, ou Deus tem seu ser a partir de um outro. E assim ele não seria o mesmo Deus, como se pressupôs, mas um outro diferente dele seria antes dele, e seria a causa de seu ser. Além disso: tudo o que é, recebe do ser e para o ser o que se torna ou é ou o que é. Portanto, se o ser for alheio a Deus, a coisa recebe o ser de outro, mas náo de Deus. Além disso: antes do ser não há nada, uma vez que quem outorga o ser cria e é criador. Porque criar é dar o ser a partir do nada. É manifesto, contudo, que todas as coisas têm o ser do mesmo ser, assim como todas as coisas brancas são brancas a partir da brancura. Por conseguinte, se o ser for diverso de Deus, o criador é outro que não Deus. Pelo contrário (4⿳0 toda coisa que tem o ser é, com exclusão de qualquer outra coisa, assim como o que tem a brancura é branco. Portanto, se o ser fosse alheio a Deus, as coisas poderiam ser sem Deus. E assim Deus não seria a causa primeira, nem a causa das coisas que são. Mais um quinto ponto: fora do ser e antes do ser existe somente o nada. Portanto, se o ser fosse diferente de Deus e alheio a Deus, Deus [náo] seria nada ou, como se disse antes, seria a partir de um outro diferente dele e anterior a ele, e aquele seria Deus de todas as coisas. O texto de Exodo 3 faz alusão ao que procede: eu sou aquele que sou. (ECKHART, Prologus generalis).

Eckhart demonstra o enunciado esse est Deus com cinco argumentaçóes de natureza lógica e com a impossibilidade de pensar o contrário. A primeira argumentação parte do seu contraditório: se o ser não fosse Deus, então Deus simplesmente não existiria, pois o ser, segundo a pressuposição, não se aplicaria 
a Ele. A alternativa possível, do ponto de vista lógico, seria: o ser aplica-se a Deus, mas não sob o modo da identidade; essa possibilidade, entretanto, não se sustenta e o porquê disso está na segunda argumentação: porque Deus não seria Deus. Schönberger comenta essa passagem com muita sutileza:

\begin{abstract}
A identidade de Deus consigo mesmo é a razão da identidade do ser com Deus. E se pode ter bem clara essa razão quando se considera que o ser, nesse caso, não é entendido apenas como um predicado formal, mas sim como uma razão determinativa. Pois, se o ser não fosse idêntico a Deus, é o que diria Eckhart, entâo Deus seria um mero caso do ser - fosse ele o caso especial que fosse - e, além disso, seria ele através do ser. No caso de sua não identidade com o ser, ele seria apenas por intermédio do ser, ou seja, através de algo diverso de si mesmo. Não aceitar uma consequência como esta já pressupóe claramente um conceito bem definido de Deus. Pois a conclusão de Eckhart só tem prosseguimento quando já se vê a Deus como primeiro. Enquanto primeiro também já se pode vê-lo como aquele que confere o ser a todas as demais coisas. (SCHÖNBERGER, 2000, p. 282-283).
\end{abstract}

Pensar em Deus como o criador de todas as coisas (e, portanto, como fundamento da realidade), sustentando também a diferença entre Deus e o ser, levaria à consequência de que as coisas devem sua existência ao ser, mas não a Deus. Dessa forma, porém, não seria possível afirmar que Deus é criador. Continua Schönberger:

[...] por um lado, Eckhart pode contrapor o ser à forma (enquanto ato do primeiro) e, por outro lado, pode compreendê-lo como a determinabilidade da essência. Sua comparaçâo elucidativa é: "omne habens esse est [...] sicut habens albedinem album est". Essa comparação ocorre com frequência. O ser é entendido como uma forma, assim como no neoplatonismo. E Eckhart afirma, de maneira muito concreta, que com a suspensão da forma nega-se também a coisa formada. Ele esclarece tal coisa, muitas vezes, com a analogia entre album e albedo, entre uma coisa branca concreta e a forma do "ser branco". Mas ele contrapóe igualmente o ser, entendido como existência, à determinação da essência. Ele utiliza este teorema sob múltiplos aspectos, por exemplo quando diz que algo só tem sua existência por meio do ato criativo de Deus, ou seja, por meio de seu ato "concedente de ser", sendo que a determinação da essência seria infundada. Ocorre essa consequência porque o conceito de essência implica a unidade de determinaçôes necessárias. Sua validaçáo não tem em si mesma nenhum momento de contingência e não depende, portanto, de nenhuma causa externa. (SCHÖNBERGER, 2000, p. 283). 
No Prologus in Opus propositionum, Eckhart retoma a sua tese esse est Deus e apresenta sua doutrina que estabelece uma relação entre o ser e as determinaçóes transcendentais:

Como o branco denota somente a qualidade, como diz o Filósofo, assim o ente denota somente o ser. De forma semelhante, acontece nos demais, por exemplo, o que é uno denota somente a unidade, o verdadeiro a verdade, o bom a bondade, o honesto a honestidade, o justo a justiça, e assim dos demais e dos seus opostos: por exemplo, o mal [denota] somente a maldade, o falso somente a falsidade, o oblíquo a obliquidade, o injusto a injustiça, e assim dos outros. Em segundo lugar, note-se antecipadamente que em um modo se deve pensar o ente e em um outro (modo) o ente [determinado] este e aquele. Semelhantemente, porém, deve-se dizer do ser absoluto e mais simples em nada acrescentado, e de outro modo do ser desta ou daquela [coisa]. No mesmo modo, contudo, diga-se de todas as outras coisas, por exemplo, do bem absoluto e em outro modo do deste bem, do bem deste e do bem para este. Pois quando digo que algo é, ou que é uno, verdadeiro e bom, e [estes termos] pertencem ao predicado como segundo adjacente, os quatro termos anunciados anteriormente devem ser entendidos em sentido formal e substantivo. Mas quando afirmo, sem dúvida, algo ser isto, por exemplo, uma pedra, e afirmo que é uma pedra, uma pedra verdadeira ou este bem, ou seja uma pedra, os quatro termos considerados anteriormente devem ser entendidos como terceiro adjacente do predicado. Logo, note-se em forma preliminar, que só Deus é propriamente ente, uno, verdadeiro e bom. Segundo: que a partir dele todas as coisas são uno, são verdadeiras e são boas. Terceiro: que a partir dele todas as coisas têm imediatamente que são, que são uno, que são verdadadeiras e que são boas. Quarto: quando digo este ente, ou [digo] este uno ou aquele, este verdadeiro e aquele, este bem e aquele, o 'este' e 'aquele' nada acrescentam de entidade, unidade, verdade ou bondade ao ente, ao uno, ao verdadeiro, ao bom. O primeiro dos quatro, quer dizer, que só Deus é propriamente ente, como é evidente em Exxodo 3: eu sou aquele que sou. Aquele que é, me enviou. E Jó: tu que somente és. No mesmo modo o Damasceno diz que o primeiro nome de Deus é "o que é”. A este propósito, cabe lembrar que Parmênides e Melisso, no Primeiro Livro da Física, admitiam um único ser, mas consideravam este ou aquele ente como múltiplo, por exemplo, o fogo e a terra e coisas semelhantes, como atesta Avicena em seu livro da Física, que ele chama Suficiência. A este propósito, pode-se lembrar Deuteronômio 6 e a Carta aos Gálatas 3: Deus é um só. Assim já é evidente a verdade da proposição proposta, na qual se diz: o ser é Deus. Por causa disso, a quem perguntar a respeito dele o quê ou quem é, se responde: ser, como em Êxodo 3: eu sou aquele que sou, e: aquele que é, como se disse antes. Novamente, diga-se o mesmo acerca do uno, isto é, que somente Deus é propriamente uno ou é unidade, como em Deuteronômio 6: um só Deus é, desde que as palavras se entendam assim: 
Deus é uno. Com isto se coaduna Proclo e o Líber de causis que expressam frequentemente Deus com o nome de uno ou de unidade. Além disso: aquele uno é negação da negação, pois que compete só ao ser primeiro e pleno, qual é Deus, a respeito do qual não se pode negar nada, já que, ao mesmo tempo, possui antecipadamente e inclui todo ser. (ECKHART, Prologus in Opus Propositionum.)

O mestre dominicano, na segunda advertência prévia, distingue o ente enquanto tal e o ente determinado hoc et hoc. A mesma coisa vale para os transcendentais, o uno, o verdadeiro e o bom. Tal distinção, antes formal, encontra uma determinação de conteúdo em quatro proposiçóes fundamentais. A primeira afirma que o ser em si, e com ele o uno, o verdadeiro e o bom, condizem somente a Deus: "Somente Deus é, propriamente, ente, uno, verdadeiro, bom, mas cada um dos restantes é, este ente, como por exemplo a pedra, o leáo, o homem etc., e este uno, este verdadeiro, este bom, como por exemplo um ânimo bom, um anjo bom, etc." (ECKHART, Prologus in Opus Propositionum.)

Segundo a tradição que deriva de João Damasceno, Eckhart cita primeiro o livro do Exxodo 3,14 (Ego sum qui sum), que expressa o verdadeiro nome de Deus. Essa citação é também o fundamento bíblico de toda a especulação cristã sobre o ser (definida por Étienne Gilson como “metafísica do Êxodo"). A segunda proposição afirma que todas as coisas possuem o ser somente a partir de Deus, assim como o ser uno, o ser verdadeiro e o ser bom: "[...] a solo deo omnia habent esse, unum esse et verum esse et bonum esse". (Prologus generalis, n. 9). Com efeito, continua Eckhart, "[...] como é que alguma coisa poderia ser se não fosse a partir do ser, ou ser uma [se não fosse] a partir do uno, ou pelo uno ou pela unidade, ou verdadeira sem verdade, ou boa a não ser pela bondade, assim como - por exemplo - tudo o que é branco é pela brancura?" (Prologus generalis, n. 9).

Em terceiro lugar, Eckhart explica que todo e qualquer ente não só possui seu ser a partir de Deus, mas o tem imediata e absolutamente, sem qualquer tipo de mediação. Finalmente, a quarta e última proposição fundamental diz como é o ser hoc et hoc em relação ao ser enquanto tal (esse absolutum): "Nada, pois, de entidade, unidade, verdade e bondade acrescentam e conferem inteiramente este ou aquele ente, este ou aquele uno, este ou aquele verdadeiro, este ou aquele bem enquanto este ou este" (Prologus generalis, n. 13). 
Das quatro proposiçôes aduzidas pelo mestre dominicano, a mais importante é a terceira: "Além do ser e sem o ser todas as coisas [não] são nada, também as coisas criadas. Portanto, se algo além de Deus outorgasse o ser, Deus não daria o ser a todas as coisas, nem influenciaria alguma, ou aquilo que daria e influenciaria seria nada" (ECKHART, Prologus generalis, n. 22).

Essa afirmação tem muita importância na espiritualidade eckhartiana e se torna um motivo fundamental da sua pregaçáo: “Todas as criaturas são um puro nada. Eu não digo que elas sejam de pouco valor ou alguma coisa: elas são um puro nada" (Pr. 4). E, no Comentário ao Evangelho de João, o dominicano afirma: "[...] em toda coisa criada se adverte a sombra do nada" (ECKHART, In Ioh, n. 20).

No texto do Prologus in Opus propositionum, cabe ainda destacar, Eckhart ressalta a unicidade do ser com uma remissão a Parmênides. A esse respeito, escreve Faggin: "[...] é significativo o fato de Eckhart citar Parmênides e Melisso, que ele conheceu através da Metafísica e da Física de Aristóteles: no Eleatismo, com efeito, expressa-se, pela primeira vez no pensamento grego de forma táo rigorosa, a exigência monística, que Eckhart devia perceber tão congenial ao seu teocentrismo" (ECKHART, 1953, p. 173).

\section{A PRIORIDADE DO INTELLIGERE EM RELAÇÃO AO ESSE}

Confrontando a teoria do ser eckhartiana presente no Opus tripartitum com as Quaestiones parisienses, fruto do primeiro magistério na Universidade de Paris, em qualidade de magister actu regens, o contraste é evidente. A primeira Quaestio parisiense, com efeito, propóe a tese ousada e original que estabelece uma prioridade do intelligere em relação ao esse:

Deve-se dizer que [o ser e o conhecer] são o mesmo quanto à coisa e talvez quanto à coisa e a noção Primeiramente introduzo as provas tais como as vi. Cinco [provas] são aduzidas na [Summa] Contra Gentiles e a sexta na primeira parte [da Summa Theologiae] e todas estão fundamentadas neste fato, que Deus é primeiro e simples. Com efeito, nada pode ser primeiro se não for simples. A primeira argumentação é porque o conhecer é um ato imanente e tudo aquilo que está no primeiro é primeiro. Portanto Deus é seu próprio conhecer e também seu ser. (ECKHART, Utrum in Deo sit idem esse et intelligere). 
Nessa questão, há um distanciamento evidente da ontologia de Tomás de Aquino, que pode ser evidenciado em dois pontos:

1) para Tomás, as realidades existentes são produzidas pelo intelecto de Deus: "Deus causa a coisa pelo seu intelecto, pois o seu ser é seu inteligir" (Summa Theologiae, Ia q. 14 a.). Eckhart não apenas torna o intelligere causa do esse na relação que intercorre entre o pensamento divino e a criação, mas sustenta que o intelecto, em Deus, possui a função de estabelecer o fundamento do ser: "Deus é intelecto e conhecer, e o próprio conhecer é fundamento do próprio ser" (ECKHART, Utrum in Deo sit idem esse et intelligere).

Portanto, a pureza e a plenitude do ser competem a Deus em virtude do intelecto, que é superior ao ser. Deus, propriamente, é intelecto e não ser: uma reflexão ontológica, por conseguinte, é apenas preliminar, não apreendendo a essência divina. Uma consideração análoga pode ser encontrada na Pregação 9, Quasi stella matutina: "Deus opera acima do ser na vastidão, onde ele pode mover-se; ele opera no não-ser. Deus operava já antes que houvesse o ser; ele operava o ser antes mesmo de haver ser" (ECKHART, Pr. 9).

2) Eckhart retoma os argumentos de Tomás de Aquino em favor da identidade de esse e intelligere em Deus, ${ }^{5}$ todavia, desde a primeira linha, ele introduz uma dúvida: "[...] dicendum quod sunt idem re et forsan re et ratione" (Utrum in Deo sit idem esse et intelligere).

Para Tomás, intelligere e esse coincidem em virtude da simplicidade divina e pelo fato de Deus ser inteligente, mas permanecem sempre distintos; Eckhart, entretanto, estabelece entre os dois conceitos uma relação unívoca afirmando, logo em seguida, que "[...] intelligere sit ipsum esse dei".

$\mathrm{Na}$ tradição tomista, apesar da identidade em Deus entre intelligere e esse, parece implícita uma superioridade do segundo em relação ao primeiro: Deus é o ser perfeito e esse é o nome mais apropriado para defini-Lo; seu intelligere é possível por causa do esse, porque Ele opera tudo através do seu ser. Contudo, é justamente essa afirmação que, para Eckhart, é problemática, de sorte que ele opera uma reviravolta sem precedentes: querendo salvaguardar o

\footnotetext{
5 "Et hoc autem quod Deus est intelligens, sequitur quod suum inteligere sit sua essentia": mas do fato de que Deus é inteligente se segue que seu conhecer é sua essência. Summa contra Gentiles, livro 1, cap. 45, n. 1. In: DE AQUINO, T., Opera Omnia. Disponível em: http://www.unav.es/filosofia/alarcon/ amicis/ctopera.html. Acesso em: 15 set. 2012.
} 
primado do intelligere, Eckhart enfatiza que a compreensão categorial de esse impede que ele seja aplicado a Deus.

$\mathrm{O}$ argumento principal que estabelece a superioridade do intelecto, na Quaestio parisiense, se desenvolve a partir da citação bíblica de João 1,1:

Em terceiro lugar demonstro como, ao meu ver, Deus não conhece porque é, mas é porque conhece; isso porque Deus é intelecto e conhecer, e o próprio conhecer é fundamento do próprio ser. Pois se diz em João 1,1: No princípio era o Verbo e o Verbo estava junto de Deus e Deus era o Verbo. (ECKHART, Utrum in Deo sit idem esse et intelligere).

Nessa passagem, o dominicano contrapóe verbum a ens e, baseando-se na citação joanina, reafirma a preeminência do primeiro em relação ao segundo, inclusive na realidade divina. A justificação disso é apresentada em forma de sequência: "Mas o evangelista não disse: em princípio era o ente e Deus era o ente. Ora, Verbo se refere totalmente ao intelecto e está aí como ação de dizer ou como palavra dita e não como ser ou ente misturado" (ECKHART, Utrum in Deo sit idem esse et intelligere).

O intelligere é fundamento, porque o Verbo "era no princípio", e o evangelista afirma que Deus é verbum e não ens. Realçando isso, Eckhart evita a polissemia da noção de esse que, pelo fato de ser sinônimo de ens, é um sujeito possível de predicados, ideia que Tomás de Aquino, ao invés, sempre rechaçou.

Prosseguindo na sua argumentaçáo, o mestre dominicano entende o ser como limitado e finito:

\begin{abstract}
Segue-se, após considerar o Verbo em João 1: Todas as coisas foram feitas por ele, para que assim se entenda: todas as coisas foram feitas por ele para que este mesmo ser convenha a elas [a essas coisas] em seguida. Por isso, o autor do De Causis afirma: "o ser é a primeira das coisas criadas". De onde, logo que alcançamos o ser, alcançamos a criatura. Portanto o ser tem, em primeiro lugar, valor de coisa criável. [...] Por isso Deus, que é criador e não é criável, é intelecto e conhecimento, e não ente ou ser. (ECKHART, Utrum in Deo sit idem esse et intelligere).
\end{abstract}

Depois dessa primeira limitação, Eckhart exclui Deus do âmbito do ser, porque Ele não pode ser confundido com a criação. A referência, agora, não é mais Tomás de Aquino, mas o Liber de Causis. O ser diz respeito somente 
à criação, enquanto, no Verbo, as coisas subsistem anteriormente ao ato de receber uma existência criada.

Para demonstrar isto assumo, primeiramente, que o conhecer é mais elevado do que o ser, e é de uma outra condiçáa. Pois todos dizemos que a obra da natureza é obra da inteligência. E, portanto, tudo o que se move é inteligente ou se reconduz a um inteligente, por quem é dirigido no seu movimento. E por isso as coisas que possuem o intelecto são mais perfeitas do que as que não o possuem, assim como no próprio devir as coisas imperfeitas ocupam o primeiro grau, de modo que no intelecto e no inteligente termino a resoluçáo assim como no sumo e perfeitíssimo. E por isso o conhecer é maior do que o ser. (ECKHART, Utrum in Deo sit idem esse et intelligere).

Pelo fato de "ser" significar "ser criado", propriedade dos entes finitos e limitados, não pode ser atribuído nem a Deus e nem ao intelecto. Os seres dotados de intelecto são os mais perfeitos, salienta o mestre dominicano, de acordo com o princípio pelo qual "[...] opus naturae est opus intelligentiae" (ECKHART, Utrum in Deo sit idem esse et intelligere).

A superioridade do intelecto se dá em virtude de ele ser princípio de todo ser e de estar acima do puro existir; o lugar dele é a alma, não como o ser que está nas coisas: "[...] as coisas que pertencem ao intelecto, enquanto tais, são não-entes" (ECKHART, Utrum in Deo sit idem esse et intelligere).

A caracterização do esse é antitética ao intelligere:

- o primeiro tem um fundamento: Deus sit universalis causa entis;

- é causado: est de ratione entis, quod sit causatum, enquanto

- $\quad$ o intelligere náo tem uma causa: de cuius ratione non est quod causam habeat,

- $\quad$ e contém virtualmente todas as coisas: in ipso intelligere omnia continentur.

Afirmando categoricamente que, em Deus, não há nem o ente nem o ser, Eckhart declara que a criação está em condição de total dependência e de absoluta distinção com respeito ao criador: "E se tu quiseres chamar o conhecer de ser, agrada-me. Digo, contudo, que se em Deus há algo que tu quiseres chamar de ser, cabe-lhe pelo próprio conhecer" (ECKHART, Utrum in Deo sit idem esse et intelligere). 
Entretanto, a um certo ponto da argumentação, o dominicano faz uma espécie de concessão, prevendo, quiçá, uma possível objeção. O ser, nesse caso, não é o ser criado, mas a puritas essendi, cujo fundamento está no intelecto: "Outrossim, o princípio nunca é o principiado, como o ponto nunca é a linha. E por isso, sendo Deus o princípio do próprio ser ou do ente, Ele não é ente ou ser da criatura; nada do que está na criatura está em Deus, a não ser como na causa e não está nele formalmente" (ECKHART, Utrum in Deo sit idem esse et intelligere).

A argumentação, em seguida, traz à tona a teoria da causalidade, todavia, aqui, o sentido de causa não é o sentido aristotélico. Eckhart entende causa como principium: todas as coisas estão virtualmente no intelecto mas, formaliter, causa e feito não podem subsistir juntos.

Outrossim, nessas coisas, que se dizem analogicamente, o que há em um dos termos análogos, não está formalmente no outro, como a saúde está no animal formalmente, enquanto na comida e na urina não existe algo de mais saudável do que na pedra. Se, portanto, todas as coisas causadas são entes formalmente, Deus não será formalmente ente. (ECKHART, Utrum in Deo sit idem esse et intelligere).

Enfim, Eckhart apresenta alguns exemplos de analogia para justificar a não-entidade de Deus, pois o analogado está formalmente em apenas um dos termos (ele cita o exemplo da saúde no animal, na comida, na urina e na pedra). Esses exemplos não deixam de ser insólitos, na estrutura da argumentação (deveria ser enfatizada, de fato, mais a presença do que a ausência do analogado em Deus). Em seguida, no Prologus in opus propositionum, o mestre dominicano usará o mesmo tipo de analogia (porém, em sentido contrário) para atribuir o ser a Deus, causa de todas as coisas, enquanto as criaturas permanecem desprovidas de ser próprio. Essa contradição, contudo, pode ser explicada como uma mudança de perspectiva que deixa inalterada a relaçáo fundamental entre Deus e a criação. Quando Eckhart afirma esse est Deus, está manifestando uma diferenciação do conceito de esse: se "ser" caracteriza o ente finito, Deus é intelligere e não há nele a ratio entis; se, ao invés, Deus é caracterizado pela puritas essendi, a criação não pode haver o ser em si mesmo. Um elemento, no entanto, permanece inalterado, quando o discurso verte sobre o ser, a saber, a referência à criação e a tentativa de compreender a relação desta com Deus: não há possibilidade de estabelecer uma comparação entre Deus e as criaturas, e a 
relação entre eles só pode seguir a direção que vai dessas para Aquele. A teoria da causalidade de Eckhart ajuda a entender esse conceito.

\section{TeOria DA CAUSALIDADE ECKHARTIANA}

O desenvolvimento mais completo dessa teoria se encontra na segunda exposição do livro do Gênesis (Líber parabolarum Genesis). Nessa obra, o dominicano alemão distingue dois tipos de causalidade: causalidade unívoca e causalidade análoga. A primeira explica a ação da causa segunda e, portanto, só tem lugar no ato segundo; a causalidade análoga, ao contrário, explica exclusivamente a ação da causa primeira e o ato primeiro. As características principais desses dois tipos de causalidade são as seguintes (MAÑÓN GARIBAY, 1999, p. 109-131):

\section{Causalidade unívoca:}

1. a causa e a coisa afetada (ou paciente) pertencem à mesma espécie ou à mesma ordem ontológica;

2. a diferença real entre a causa e a coisa paciente se dá em virtude da matéria;

3. por causa da matéria, o efeito da causa sobre a coisa paciente é limitado;

4. o efeito da causa sobre a coisa paciente diminui conforme a atuação da causa;

5. a causa padece também em sua ação sobre a coisa afetada;

6. a causa e a coisa afetada se tornam semelhantes no processo causal;

7. o efeito da causa perdura na coisa paciente, ainda que a causa não continue presente. A causa se encontra dentro de uma série de causas, isto é, na causalidade unívoca não há primeira causa.

\section{Causalidade análoga:}

1. a causa e a coisa paciente não têm a mesma espécie em comum, ou não pertencem à mesma ordem ontológica;

2. a coisa nunca é afetada por nenhuma outra causa, ou é primeira causa da coisa paciente que afeta; 
3. no efeito da causa, não perdura a coisa paciente, quando a causa não está presente; isto é, a ação da causa sobre a coisa paciente é direta, sem depender de algum meio para afetar a coisa paciente;

4. a coisa paciente nunca se apropria do efeito produzido pela causa, mas depende constantemente da ação da causa para ser afetada;

5. a coisa afetada remete constantemente à causa para justificar ou explicar a ação do efeito;

6. a causa não se vê afetada pela ação do seu efeito na coisa paciente; ou seja, não há nenhuma coação que obrigue a causa a atuar ou alguma dependência da causa em relação ao efeito. Por isso, mesmo a coisa paciente padece a açáo da causa sem induzir a causa a atuar.

Pelo fato de a causalidade análoga ser um meio para explicar a criação divina, ou a relação entre Deus e as criaturas, foi a que recebeu maior atenção nos escritos de Eckhart. Conforme Mañon Garibay, o mestre dominicano distingue um duplo efeito como resultado da ação da causa primeira:

1. um ser indiferenciado e invariável das criaturas na sua ideia, causa ou palavra divina;

2. um ser diferenciado e variável das criaturas fora da causa ou palavra divina, em sua existência exterior (extrastantia).

Operando essa distinção, Eckhart afirma com Agostinho que a cada criatura corresponde um duplo ser, a saber: para criar o mundo, Deus usa a sua palavra, segundo o relato do Gênesis: "Deus disse: 'Que exista a luz'; e a luz foi feita” (Gen 1,3). A palavra de Deus, em hebraico, é dabar, palavra-evento: no mesmo instante em que é pronunciada, ela cria. O que essa palavra expressa é a essência mesma da causa e, por isso, a palavra é distinta da sua causa, mas não ontologicamente diferente. Por causa disso e, apoiando-se no princípio de causalidade eficiente de Aristóteles, "Eckhart não fala de causalidade nessa etapa do processo de criação, mas de produção (productio), pois há uma diferença real ou ontológica entre causa e coisa afetada. E, pelo fato de a palavra ser expressáo da essência da causa, a palavra é filho ou Verbo divino" (MAÑÓN GARIBAY, 1999, p. 114). Todavia, se, por um lado, a palavra de Deus é expressão da essência de Deus (segundo a causalidade unívoca), do outro, é princípio das criaturas (de acordo com a causalidade análoga). Com base nesta última, o mestre dominicano faz a distinção entre ser necessário (a causa primeira) e ser 
contingente (a criatura): "Eckhart toma a diferença entre causa primeira e ser criado como critério para distinguir ser necessário e ser contingente e também para evitar, em última instância, que se possa pensar em algum tipo de panteísmo no seu pensamento" (MAÑÓN GARIBAY, 1999, p. 117). Para alguns autores, a melhor distinção entre Deus e as criaturas é a de Tomás de Aquino (em Deus há identidade de essência e existência, enquanto nas criaturas elas permanecem distintas); contudo, o exemplo histórico de Meister Eckhart contradiz, de certa forma, essa interpretação da escolástica da Alta Idade Média: “[...] a melhor distinção entre Deus e as criaturas só pode determinar-se considerando a intenção do autor, e a intenção de Eckhart só pode ser apreendida na teoria da unidade" (MAÑÓN GARIBAY, 1999, p. 117).

\section{Conclusão: A IDENTIDAde da ESSÊNCIA ENTRE DeUS E O FUNdo da ALMA}

A relação entre Deus e a criatura traz à tona o conceito de analogia, que é um teorema central no pensamento do último Eckhart. A obra em que ele mais desenvolve esse conceito é a segunda lectio super Ecclesiasticus (n. 52-53):

É necessário considerar a distinçấo entre unívoco, equívoco e análogo. De fato, os equívocos se distinguem pelas coisas diferentes significadas, os unívocos pelas diversidades da mesma coisa, os análogos, porém, não se distinguem nem pelas coisas e nem pelas diversidades das coisas, e sim «através dos modos» de uma mesma coisa em absoluto. Por exemplo: a mesma saúde que está no ser vivente - e não outra - está também na comida e na urina e, todavia, de uma tal forma que, nada da saúde enquanto tal está absolutamente na comida e na urina, não mais daquilo que há em uma pedra. A urina, entretanto, se diz saudável somente por ela indicar aquela saúde que está no ser vivente. [...] Mas o ente ou o ser e todas as perfeiçóes, sobretudo as perfeiçóes gerais - ser, uno, verdadeiro, bom, luz, justiça, etc. - são atribuídas a Deus e às criaturas em modo analógico. Disso temse como consequência que a bondade, a justiça e coisas semelhantes têm completamente sua própria bondade a partir de algo que é exterior, com o qual elas têm uma relação analógica, ou seja, Deus. (In Eccl.).

Em seguida, Eckhart, cita dois trechos das Confissóes de Agostinho (do livro primeiro e do livro terceiro), para confirmar suas afirmaçóes. E prossegue:

É possível resumir a demonstraçấo no modo seguinte: os entes que estão em uma relação de analogia não têm, em si mesmos, nenhum fundamento na forma segundo a qual estão nessa relação. Mas todo ente criado está em uma relação analógica com Deus quanto ao ser, à verdade e à bondade. 
Portanto, todo ente criado tem o ser, o viver, o saber, em sentido positivo e radical, através de Deus e em Deus, não em si mesmo como ente criado. (In Eccl.).

A analogia de Eckhart, como observa Ruh (RUH, 1989, p. 122-123), é uma analogia attributionis, na qual o analogado principal se comunica plenamente, mas, ao mesmo tempo, oculta-se nos seus membros. Ela se distingue da analogia proportionalis de Tomás de Aquino, com a qual ele visa a,

[...] por um lado, evitar o obstáculo do panteísmo e, por outro, salvar a continuidade lógica do relativo ao Absoluto: a univocidade dos atributos em Deus e nas criaturas levaria à imanência, enquanto sua equivocidade faria de Deus um nome oco e insignificante "porque, segundo isto, as criaturas não poderiam conhecer nem demonstrar nada acerca de Deus; sempre se cairia na falácia do erro". (FAGGIN, 1983, p. 61).

Por meio da analogia proportionalis, Tomás afirma que o ser é inerente a todos os membros da analogia formalmente (ou seja, segundo a sua própria natureza, sendo que há um só ser), desde o homem até à pedra, mas é diferente o modo de ser: em Deus uno, absoluto, perfeito; na criatura, como participação. Segundo a fórmula simplificada dessa analogia, Deus é o ser, enquanto a criatura tem o ser. Meister Eckhart, ao invés, opera a passagem da analogia Deus-criatura à univocidade Deus-fundo da alma, o que significa a identidade de essência.

RASCHIETTI, Matteo. Being and the one in the thought of Meister Eckhart. Trans/Form/ Ação, Marília, v. 35, p. 79-98, 2012. Edição Especial.

\begin{abstract}
The fundamental problem of Eckhartian speculation is that of the connection between the truth of the unique being as God and the question of His knowledge. By creating a synthesis of the Augustinian-Platonic tradition and the thought of Pseudo-Dionysius the Areopagite, the Dominican master founds the basis of his unitary theology in the theory of being.
\end{abstract}

KEYWORDS: One. Being. Knowledge. Analogy. Causality. 


\section{REFERÊNCIAS}

CAVICCHIOLI, C. Metafísica del Verbo e mistica trinitaria in Meister Eckhart (Parte $I^{a}$ ). In: Sapienza - Rivista trimestrale di filosofia e teologia dei Domenicani d'Italia, ${ }^{\circ}$. 50 (1997).

DE AQUINO, T., Opera Omnia. Disponível em: http://www.unav.es/filosofia/alarcon/ amicis/ ctopera.html. Acesso em: 01 out. 2012.

ECKHART, M. Deutsche Predigten und Traktate. Joseph Quint (Org.). München: Carl Hanser Verlag, 1955.

. Utrum in Deo sit idem esse et intelligere. Deutsche Werke II - Lateinische Werke, Deutsche Klassiker Verlag, Frankfurt am Main, 2008.

. Die Leteineische Werke. E. Benz, B. Decker. J. Koch, L. Sturlese. Stuttgart-Berlin: LW I (Konrad Weiss, 1938-64): Prologi in Opus tripartitum, in Opus propositionum, in Opus expositionum. Expositio libri Genesis et Libri Exodi. Liber Parabolarum Genesis. LW II (1954-75): Expositio libri Exodi, Sermones et Lectiones super Ecclesiastici, Expositio Libri Sapientiae, Expositio Cantici Canticorum.

. O livro da Divina Consolação e outros textos seletos. 4. ed. Petrópolis: Vozes, 1999.

. Expositio Libri Genesis. Edição bilingue latim-francês: Le Commentaire de la Genèse

précédé des Prologues (Org.). A. De Libera, E. Wéber, E. Zum Brunn. Paris: Les Éditions du Cerf, 1984.

La Nascita Eterna - Antologia sistematica delle opere latine e tedesche. Firenze: Sansoni ed., 1953. Introdução e notas: G. Faggin.

DE LIBERA, A. La mystique rhénane, d'Albert le Grand à Maître Eckhart. Paris: Éditions du Seuil, 1994.

FAGGIN, G. Meister Eckhart e a mistica medieval alemã. São Paulo: ECE, 1983.

GILSON, E. L’esprit de la philosophie médiévale. Paris: Vrin, 1931.

LOSSKY, V. Théologie Négative et connaissance de Dieu chez Maître Eckhart. Paris: Librairie Philosophique, 1998.

MAÑÓN GARIBAY, G. Identidad y diferencia en la filosofía del Maestro Eckhart. Aná Mnesis - Revista semestral de investigación teológica publicada por los frailes dominicos de la provincia de Santiago de México, IX, n. 2, 1999

RUH, K. Meister Eckhart. Teologo, Predicatore, Mistico. Brescia: Morcelliana, 1989.

SCHÖNBERGER, R. Meister Eckhart: pensamento e interiorizaçấo do Uno. In: KOBUSCH, T. (Org.). Filósofos na Idade Média. Uma introdução. São Leopoldo (RS): Editora Unisinos, 2000 (Coleção História da Filosofia). 
RASCHIETTI, $M$. 